University of Nebraska - Lincoln

DigitalCommons@University of Nebraska - Lincoln

Faculty Publications from the Department of Electrical \& Computer Engineering, Department Electrical and Computer Engineering

2011

Series-Connected Self-Reconfigurable Multicell Battery

Taesic Kim

University of Nebraska-Lincoln

Wei Qiao

University of Nebraska-Lincoln, wqiao@engr.unl.edu

Liyan Qu

University of Nebraska-Lincoln, lqu2@unl.edu

Follow this and additional works at: https://digitalcommons.unl.edu/electricalengineeringfacpub

Part of the Electrical and Computer Engineering Commons

Kim, Taesic; Qiao, Wei; and Qu, Liyan, "Series-Connected Self-Reconfigurable Multicell Battery" (2011). Faculty Publications from the Department of Electrical and Computer Engineering. 173.

https://digitalcommons.unl.edu/electricalengineeringfacpub/173

This Article is brought to you for free and open access by the Electrical \& Computer Engineering, Department of at DigitalCommons@University of Nebraska - Lincoln. It has been accepted for inclusion in Faculty Publications from the Department of Electrical and Computer Engineering by an authorized administrator of DigitalCommons@University of Nebraska - Lincoln. 


\title{
Series-Connected Self-Reconfigurable Multicell Battery
}

\author{
Taesic Kim, Wei Qiao, and Liyan Qu \\ Department of Electrical Engineering \\ University of Nebraska-Lincoln \\ Lincoln, NE 68588-0511 USA \\ wqiao@engr.unl.edu; liyanqu@ieee.org
}

\begin{abstract}
This paper proposes a novel series-connected, selfreconfigurable, multicell battery design. A new cell switching circuit topology is proposed and implemented by using highefficiency semiconductor devices for dynamic configuration of the multicell battery. Each cell in the battery only uses two switches to fully control its operation independently. The proposed design can maximally utilize the battery's capacity and is tolerant to failures of single or multiple cells. These prolong the operating time and lifespan and enhance the reliability of the battery system. By using the proposed design, additional monitoring, control, protection and optimization functions can be readily added to each cell and the battery system to produce a smart battery. The proposed design is validated by simulation and experimental results for a six-cell polymer lithium-ion battery pack. The proposed design is universal and can be applied to any type and size of battery cells.
\end{abstract}

\section{INTRODUCTION}

The traditional multicell battery design usually employs a fixed configuration to connect multiple cells in series during operation in order to achieve the required voltage level [1]. However, cell state variations are commonly present in series-connected multicell batteries. In this case, the fixedconfiguration design can only utilize a part of the total battery capacity, which reduces the operating time and lifespan of the battery system. Moreover, the fixed configuration has low reliability and low fault tolerance because the failure of any single cell during operation will result in the failure of the whole battery system.

A commonly used method to solve the problem of cell state variations is using a cell balancing circuit. However, most existing balancing circuits use dissipative resistors, resulting in energy loss [2]. The latest products of cell balancing integrated circuits (ICs) [3] use electronic converters to transfer charge from cell to cell during operation. However, this solution increases the cost and volume of the battery system. Moreover, most of these cell balancing ICs were developed for small multicell batteries in portable electronic devices. No such circuits are available for large-scale battery systems as yet. The state-of-the-art batteries have safety circuits to protect them from high temperature, overcharge, and over-discharge by monitoring the temperature, voltage, and current of each cell. However, lacking an effectively reconfigurable topology, the safety circuits will cut off the whole battery system when any single cell is operated in these abnormal conditions. Recently, several reconfigurable multicell battery topologies have been proposed for portable electronic devices [4]-[6]. However, these topologies are too complex and unrealistic for the battery systems with large numbers of cells.

This paper proposes a new series-connected, selfreconfigurable, multicell battery design. A new cell switching circuit topology is proposed where each cell can be controlled independently and only uses two switches to fully control its charge, discharge, and cutoff. The resulting battery system can be operated with variable terminal voltages to reduce losses in converters [6]. The cell switching circuit and the control circuit for each cell are designed and implemented by using high-efficiency semiconductor devices. Compared to existing reconfigurable battery designs, the number of switches in the proposed design is significantly reduced. This reduces the cost, complexity, and control effort of the battery system and facilitates the reconfiguration process. By controlling the switches, each cell can operate independently with different charge/discharge methods. For example, through a pulsed discharge method, the recovery effect can be effectively utilized to improve the discharge efficiency of the battery [7]-[9]. The proposed design can maximally utilize the battery's capacity, thereby maximizing the operating time of the battery system. Moreover, the proposed design is tolerant to failures of single or multiple cells, thereby enhancing the reliability of the battery system. The proposed design is validated by simulation and experimental studies for a sixcell polymer lithium-ion battery pack. The proposed design is universal and can be applied to any type and size of battery cells.

This work was supported by the U.S. National Science Foundation under CAREER Award ECCS-0954938. 


\section{Proposed Series-Connected, Reconfigurable, MUlticell BATTERY DESIGN}

The proposed design consists of three parts: (1) a series cell array, (2) a cell switching circuit, and (3) a control circuit, as shown in Fig. 1.

\section{A. Series Cell Array}

The nominal voltages of most single rechargeable battery cells are limited to several volts, e.g., $3.7 \mathrm{~V}$ for the polymer lithium-ion battery cells used in this paper, which are much lower than the voltages required in many applications. Fig. 1 shows a series cell array in which all battery cells are connected in series by the cell switching circuit to meet the voltage required for certain applications. Moreover, multiple series cell arrays can be connected in parallel to meet a higher current requirement, which however is not within the scope of this paper.

\section{B. Cell Switching Circuit}

Fig. 2 shows the proposed topologies for the cell switching circuit used for connecting/disconnecting the cells and reconfiguration of the series cell array. Only $2 \mathrm{n}$ controllable power switches are needed to form the cell switching circuit for an array with $\mathrm{n}$ cells in the topology. Each cell uses two controllable power switches, e.g., the switches Sk1 and Sk2 for Cell k $(\mathrm{k}=1, \cdots, \mathrm{n})$, which turn on/off alternatively to connect/cut off the cell from the array. The cell switching circuit is designed to meet the following specifications to make the battery pack reconfigurable during the operation. First, the cell switching circuit can connect any cell in series with others in the array if needed. For example, if Cell k needs to be connected, then Sk1 turns on and Sk2 turns off. When Cell k is connected, it should be able to operate in both charge and discharge modes, which is controlled by Sk1. Second, the cell switching circuit can cut off any single or multiple cells from the array if needed. For example, if Cell $\mathrm{k}$ needs to be cut off from the array to prevent it from overcharge in the charge mode or from overdischarge in the discharge mode, then Sk1 turns off and Sk2 turns on. Turning on Sk2 ensures that Cells $\mathrm{k}+1, \cdots, \mathrm{n}$ can be

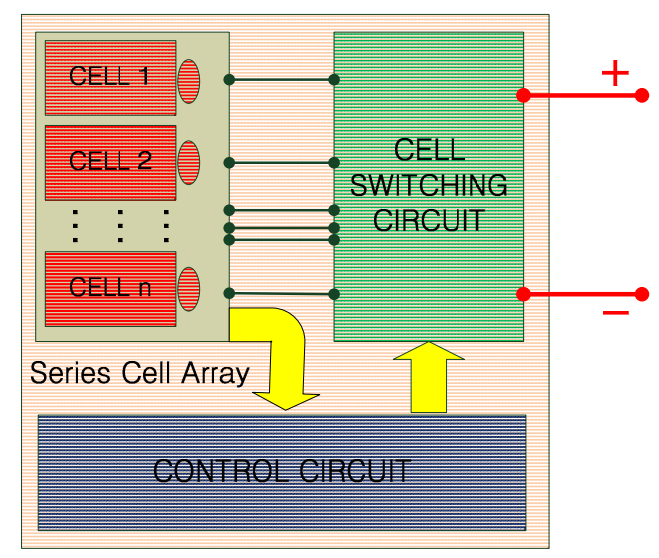

Fig. 1. The proposed self-reconfigurable, multicell battery design.

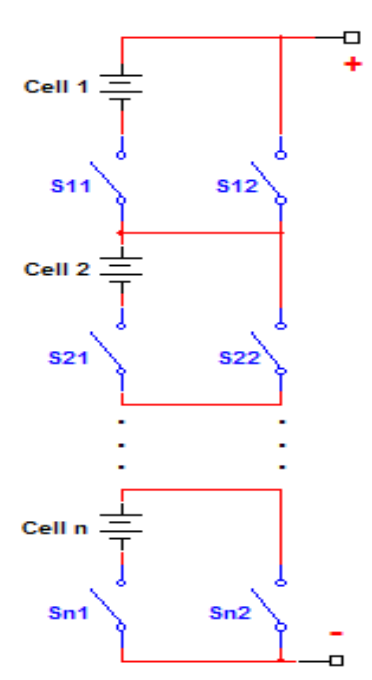

Fig. 2. The proposed self-reconfigurable, multicell battery design.

connected in the array to supply (discharge) or store (charge) energy through the terminals of the battery pack. Therefore, these two specifications require all switches to conduct current in two directions. Additionally, each switch should have a negligible conduction loss so that the reconfigurable capability is not obtained at a cost of unacceptably reduced battery efficiency. In this application, switching losses are not a concern because it typically takes a long time, e.g., 30 minutes or longer, for a switch to change its state. Highefficiency power MOSFETs are a good candidate for implementation of the switches in the cell switching circuit. The power MOSFETs can conduct bi-directional currents and have a negligible conduction loss because of their negligible on resistance, not to mention low cost. In the proposed design, it is important to connect the MOSFETs in the correct direction. The anode of body diode of MOSFET Sk1 should be connected to the negative terminal of the cell $\mathrm{k}$. This connection can block the unwanted discharges of the cell $\mathrm{k}$. On the other hand, the cathode of body diode of MOSFET Sk2 should be connected to the positive terminal of the cell, which prohibits the unwanted charges flowing through the body diode of the power MOSFET to Cells $\mathrm{k}+1$, $\cdots, \mathrm{n}$ when Cell $\mathrm{k}$ is connected in the array, i.e., Sk1 is on.

Fig. 3 illustrates a switch implementation for Cell $\mathrm{k}(\mathrm{k}=$ $1, \cdots, \mathrm{n})$ using an $\mathrm{n}$-channel power MOSFET (Sk1) and a pchannel power MOSFET (Sk2) with the gate drive circuit and control module. The gate drive circuit is implemented by using four low-cost, small-signal BJTs, which only use the voltage of Cell $\mathrm{k}$; no additional voltage source is required. When $\mathrm{Qk} 1$ turns on, it drives Qk2 on, which turns on the power MOSFET Sk1 by using the voltage of Cell $\mathrm{k}$. Turning off Sk1 is accomplished by Qk3, which discharges the parasitic capacitor between the gate and source terminals of Sk1 when Qk1 turns off. Sk2 is turned on when Qk4 turns on, which provides a gate signal to charge the parasitic capacitor between the source and gate terminals of Sk2 to turn on the p-channel MOSFET Sk2. Two 15-V Zener diodes, Dzk1 and Dzk2, are used to prevent the high-side voltage of the gate 
drive exceeding the maximum value of $V_{g s}$ of $\mathrm{Sk} 1$ and the maximum value of $V_{s g}$ of $\mathrm{Sk} 2$, respectively. In this switching implementation, an n-channel MOSFET with a low threshold $V_{g s}$ (e.g., 1.5 2 V) should be used for Sk1. The selection of the components in the gate drive circuit ensures that the energy consumption of the gate drive circuit is negligible compared to the energy flow in the cell and the transient switching period is minimized to prevent short circuit between Sk1 and Sk2. In [10], the authors have proposed a cell switching implementation, which however requires an additional voltage source for the gate drive circuit. Since the gate drive circuit shares the same ground with the MOSFET switching circuit and due to the voltage limitation of the small-signal BJTs, the application of the switching implementation in [10] is limited to low-voltage (e.g., $<60$ V) battery systems only. Compared to the switching implementation in [10], the new switching implementation in Fig. 3 removes the need of an additional voltage source for the gate drive circuit. Therefore, the new switching implementation can be used for multicell battery systems at any voltage levels.

\section{Control Module}

The control circuit is designed to generate signals to control on/off of the power MOSFETs. Each cell has a control module, which generates gate signals for two smallsignal BJTs, Qk1 and Qk4, to drive the corresponding power MOSFETs, as shown in Fig. 3. The control modules of all the cells form the control circuit in Fig. 1. Fig. 4 shows the schematic diagram of a control module, which consists of a monitoring circuit, comparators, and a signal generator. The monitoring circuit performs the functions, such as monitoring the voltage, current and temperature, tracking the state of charge (SOC), etc., for each cell. A basic function of the control circuit in this paper is to protect the battery cells from overcharge and over-discharge during operation. Fig. 5 shows the voltage monitoring circuit for one cell, which uses differential op-amps and high precision $(0.1 \%)$ resistors to generate the input signal (i.e., the cell operating voltage) for the comparators in Fig. 4. The voltage comparators compare

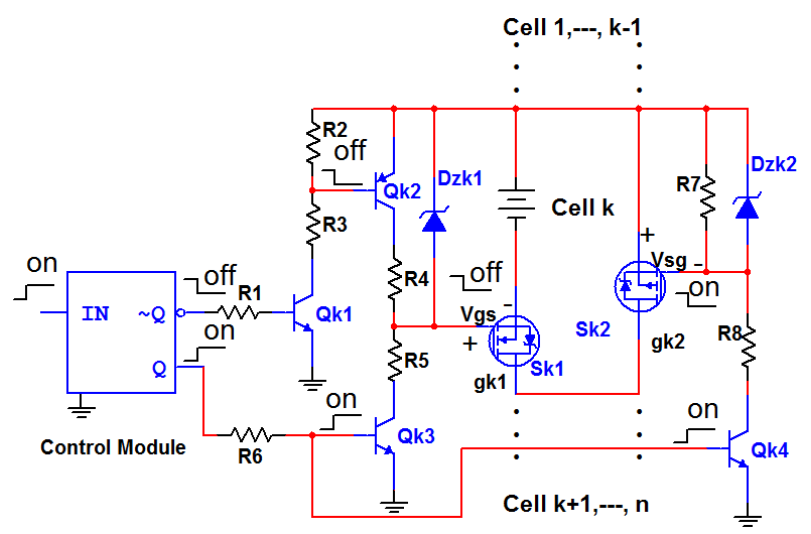

Fig. 3. A switch implementation for Cell $\mathrm{k}(\mathrm{k}=1, \cdots, \mathrm{n})$ using an $\mathrm{n}$ - channel power MOSFET and a p-channel power MOSFET with the gate drive circuit and the control module.

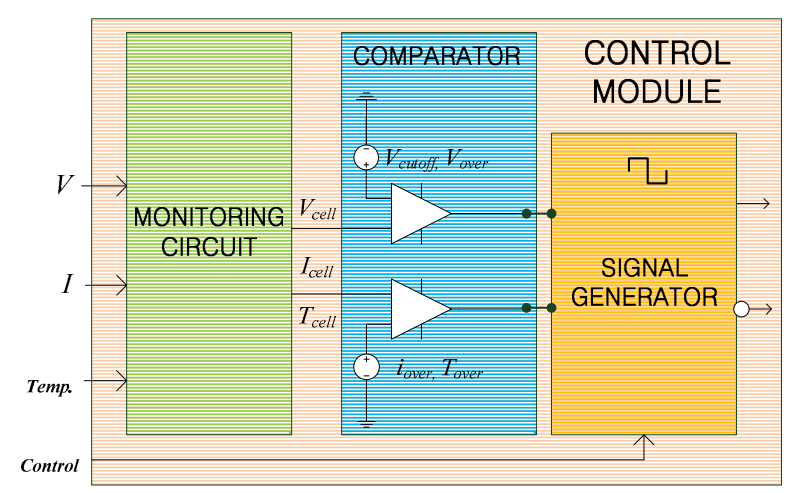

Fig. 4. Schematic diagram of the control module.

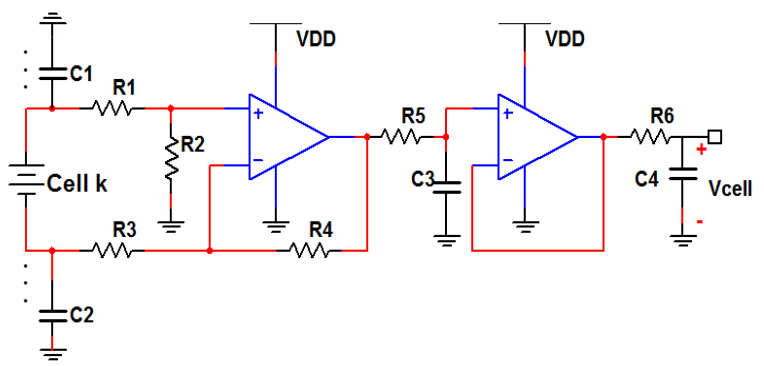

Fig. 5. The cell voltage monitoring circuit

the operating voltage of the cell with the designated discharge and charge cutoff voltages, $V_{\text {cutoff }}$ and $V_{\text {over }}$, respectively, to protect the cell from overcharge and overdischarge during operation. The outputs of the comparators indicate the operating states of the cell and are used by the signal generator to generate the gate signals to turn on/off the two small-signal BJTs, Qk1 and Qk4. Additional monitoring, control, protection and optimization functions can be added to the control module.

\section{Modeling OF BAtTery Cells}

An accurate battery cell model is needed in order to validate the proposed design by simulation studies. Moreover, monitoring, control, protection, and optimization of the battery systems also need an accurate battery cell model for SOC tracking, etc. In this paper, a hybrid battery

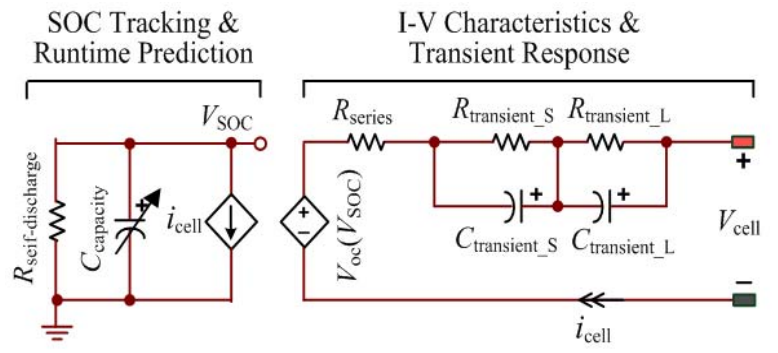

Fig. 6. The electrical circuit-based hybrid battery cell model. 


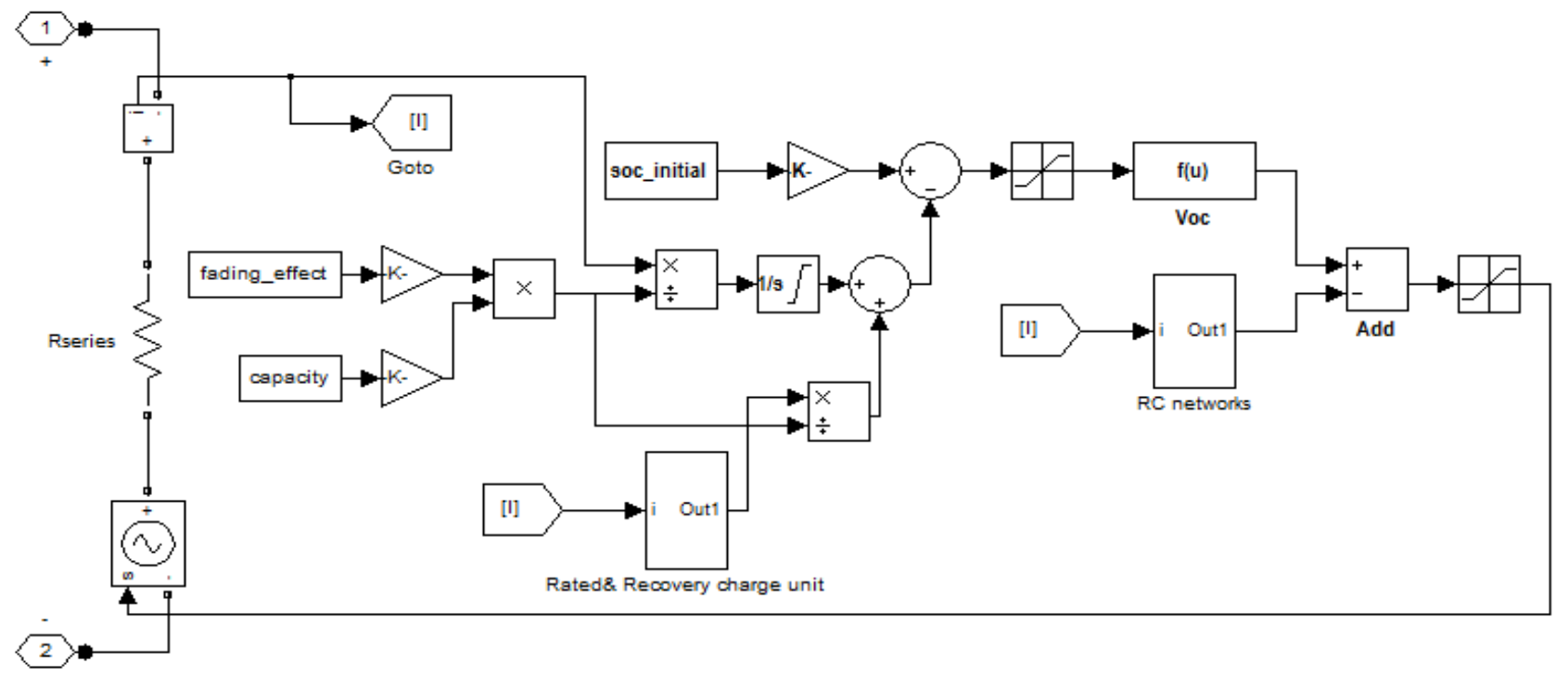

Fig. 7. The hybrid single cell model implemented in MATLAB/Simulink.

model, as shown in Fig. 6, is used, which combines an electrical battery cell model [11] with a kinetic battery cell model (KiBaM) [12]. The former can accurately capture the $\mathrm{I}-\mathrm{V}$ characteristics and transient response of a battery cell; while the latter can compensate for the nonlinear effects, such as the recovery effect and rated capacity effect, of the battery cell. Therefore, the hybrid model can accurately predict the runtime and I-V performance of the cell while taking into account the effects of temperature and capacity fading on the cell dynamics. A self-discharge resistor $\left(R_{\text {self- }}\right.$ discharge), a variable capacitor $\left(C_{\text {capacity }}\right)$, and a currentcontrolled current source are used for SOC tracking and runtime prediction. A voltage-controlled voltage source is used to bridge the SOC to the battery open-circuit voltage $\left(V_{O C}\right)$. The open-circuit voltage, internal series resistance $\left(R_{\text {series }}\right)$, and resistor-capacitor ( $\left.\mathrm{RC}\right)$ network emulate the I-V characteristics and transient response of the cell.

Fig. 7 shows the implementation of the hybrid battery cell model in MATLAB/Simulink. The rated \& recovery charge unit offers the nonlinear capacity variation by changing the value of $C_{\text {capacity }}$ during battery operation. All circuit components are implemented by using the standard modules from the SimPowerSystems toolbox.

\section{Simulation RESUlT}

A six-cell battery bank is built by using the proposed design and is simulated in MATLAB/Simulink. Each cell is a 3.7-V, 860-mAh lithium polymer cell, which is modeled by the battery model in Section III. Assuming the initial SOCs of Cells $2-5$ are all at $100 \%$, Fig. 8 compare the total energy in Wh that can be supplied by the fixed-configuration, sixcell battery and the proposed self-reconfigurable, six-cell battery for different SOCs of Cells 1 and 6. These results clearly show that the proposed design significantly improves the energy usage of this multicell battery. For example, when the SOC of Cell 1 or 6 or both becomes zero, the whole

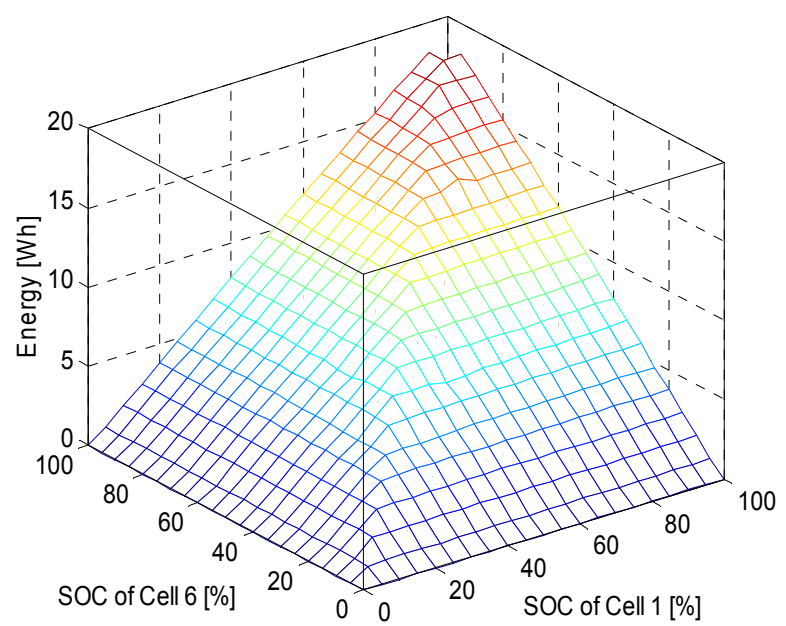

(a)

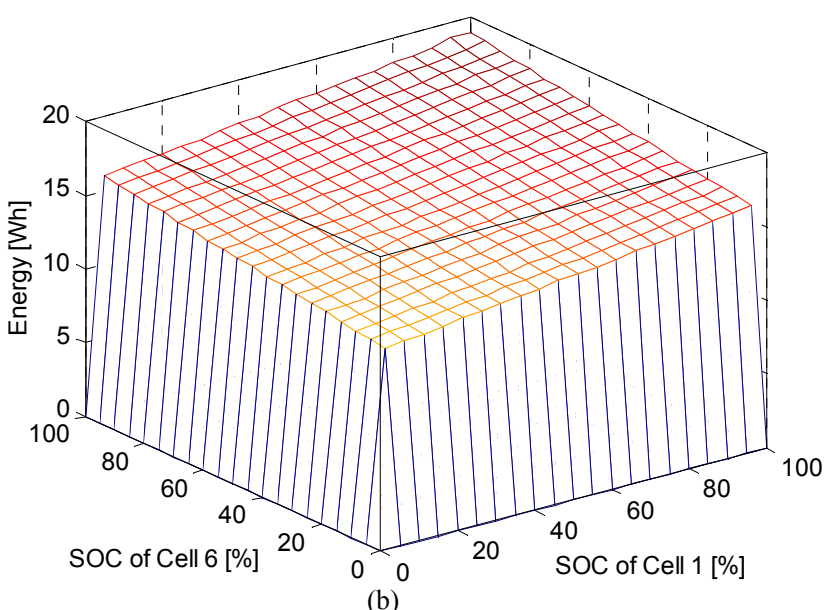

Fig. 8. Total energy in Wh that can be supplied by (a) the fixedconfiguration, six-cell battery; (b) the proposed self -reconfigurable, sixcell battery. 
battery with the fixed configuration has to be cut off and cannot supply any energy to the load although the usable capacity of the battery is still significant. On the other hand, the proposed self-reconfigurable battery can supply energy from other cells even the SOC of one or both of Cells 1 and 6 becomes zero. For example, in the worst case when the SOCs of Cells 1 and 6 are both zero, the reconfigurable battery can still supply totally 12.728 Wh energy from Cells $2-5$, which is $66.7 \%$ of the maximum energy capacity of the battery system.

\section{EXPERIMENTAL RESULTS}

The six-cell battery used in simulation studies is constructed in hardware to further validate the proposed design by using the polymer lithium-ion battery cells. Fig. 9 illustrates the experimental setup. The cells are charged by a variable DC source and discharged through a programmable DC electronic load, which offers Constant Resistor (C.R), Constant Current (C.C), and Pulse Current (P.C) modes. Twelve high-efficiency power MOSFETs are used to form the cell switching circuit on a printed circuit board (PCB). The sensing, control and protection functions are also implemented on the PCB. The sensed information is used for real-time control and protection of the battery pack. Experiments are performed at different scenarios to compare with the corresponding simulation results to validate the proposed design. The results are listed in Table 1. For all scenarios, the experimental results agree with the simulation results. Figs. 10 and 11 compare the terminal voltage responses of the self-reconfigurable, six-cell battery obtained from simulations and experiments for Scenarios 1 and 3, respectively.

In Scenario 1, the six cells are discharged using the C.R. mode simultaneously. Since the initial SOCs of the cells are different, the cells are fully discharged sequentially. Once a cell is fully discharged, it will be disconnected from the battery pack by the cell switching circuit but the remaining cells still provide energy to the load. The results show that not only the steady-state but also the dynamic responses of the battery obtained from simulations agree with those from experiments. Therefore, the comparison in Fig. 8 is effective to validate the superiority of the proposed self-reconfigurable battery over the traditional fixed-configuration battery.

In Scenario 2, all six cells are discharged simultaneously using the C.C. method. In Scenario 3, the six cells are divided into two groups and each group has three cells. The two groups of cells are discharged alternatively, i.e., pulsed discharge (P.C.), with a time interval of $300 \mathrm{~s}$ until all the cells are fully discharged. Fig. 11 shows that by using the cell switching circuit, the self-reconfigurable, six-cell battery provides energy to the load with the desired terminal voltage of $\sim 12 \mathrm{~V}$ during operation. As shown in Table 1, compared to using the C.C. discharge (Scenario 2), more energy (600 $\mathrm{mWh}$ ) is supplied by the self-reconfigurable, six-cell battery when using the P.C. discharge (Scenario 3). This P.C. discharge method utilizes the recovery effect to improve the energy conversion efficiency of the battery cells, which however cannot be achieved by the traditional fixedconfiguration battery design.

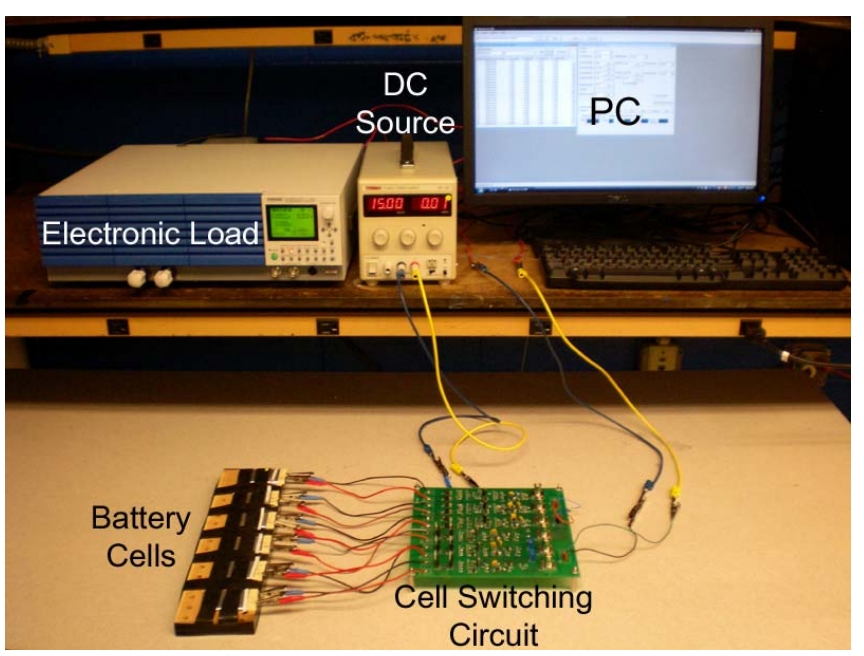

Fig. 9. Experimental setup.

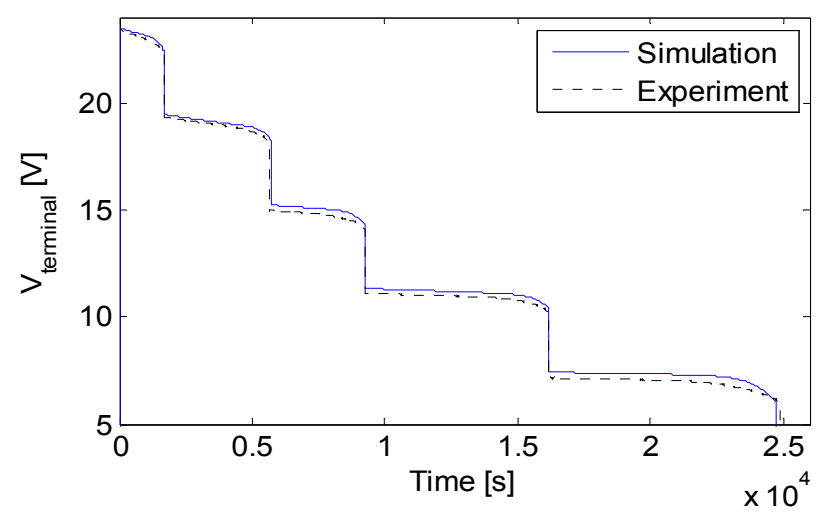

Fig.10. Comparison of simulation and experimental results in Scenario 1 for the terminal voltage of the battery.

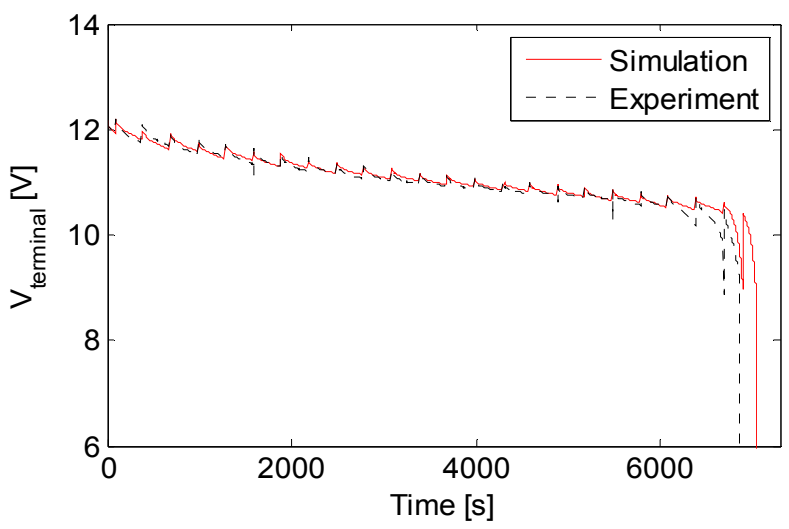

Fig.11. Comparison of simulation and experimental results in Scenario 3 for the terminal voltage of the battery. 
Table 1: Comparison of simulation and experimental results

\begin{tabular}{|c|c|c|c|c|c|c|c|c|c|}
\hline \multirow{2}{*}{ Scenario } & \multirow{2}{*}{\begin{tabular}{c} 
Discharge method \\
\cline { 2 - 10 }
\end{tabular}} & \multicolumn{4}{|c|}{ Cell condition expressed by SOC [\%] } & \multicolumn{3}{|c|}{ Energy [Wh] } \\
\cline { 2 - 10 } & Cell 1 & Cell 2 & Cell 3 & Cell 4 & Cell 5 & Cell 6 & Simulation & Experiment \\
\hline 1 & C.R. $=100 \Omega$ & 100 & 80 & 55 & 38 & 13 & 100 & 12.38 & 12.28 \\
\hline 3 & C.C. $=860 \mathrm{~mA}$ & 100 & 100 & 100 & 100 & 100 & 100 & 18.41 & 18.30 \\
\hline
\end{tabular}

In the worst scenario where all the cells are operated at the rated voltage of $3.7 \mathrm{~V}$ and the maximum current of $1.6 \mathrm{~A}$, the conduction loss of the power MOSFETs in the six-cell battery pack is approximately $64 \mathrm{~mW}$ and the total power loss of the gate drive and control circuits is approximately $200 \mathrm{~mW}$. Therefore, the efficiency of the battery system is higher than $98 \%$ and can be further improved by using higher-efficiency devices.

\section{CONCLUSION}

This paper has presented a novel series-connected, selfreconfigurable, multicell battery design. A new switching circuit topology has been proposed where each cell in the battery only uses two switches to fully control its operation independently. The switching circuit and the control circuit for each cell have been designed and implemented by using high-efficiency semiconductor devices. The proposed design can maximally utilize the battery's capacity and is tolerant to failures of single or multiple cells, thereby maximizing the operating time and lifespan and enhancing the reliability of the battery. By using the proposed design, additional monitoring, control, protection, and optimization functions can be readily added to each cell and the overall battery system. Simulation and experimental results have shown a remarkably improved energy usage of multicell batteries using the proposed design.

\section{APPENDIX}

The parameters of the components used in the simulation and experimental studies are listed as follows.

1) Battery cell: pl-383562 2C (polymer lithium-ion); nominal voltage: $3.7 \mathrm{~V}$; nominal capacity: $860 \mathrm{mAh}$; discharge cutoff voltage $\left(V_{\text {cutoff }}\right): 3 \mathrm{~V}$; charge cutoff voltage $\left(V_{\text {over }}\right)$ : $4.2 \mathrm{~V}$; maximum discharge current: $2 \mathrm{C}$.

2) Power MOSFET: n-Channel MOSFET; FDP8441 (S41, S42, S51, S52, S61, and S62), $V_{D S S}=40 \mathrm{~V}, R_{D S(\text { on })}=$ $2.1 \mathrm{~m} \Omega$, STD90N02L (S31, S21, and S11), $V_{D S S}=25 \mathrm{~V}$, $R_{D S(\text { on })}=5.2 \mathrm{~m} \Omega, V_{\text {th }}=1.8 \mathrm{~V}$; p-Channel MOSFET: AOD403(S32, S22, S12), $V_{D S S}=-30 \mathrm{~V}, R_{D S(\text { on })}=6.2 \mathrm{~m} \Omega$, $V_{\text {th }}=-2.5 \mathrm{~V}$

3) Small-signal transistor: MMBT 2222, MMBT 2907.

4) Resistors in the power MOSFET gate drive and control circuit (Fig. 3): R1 = $10 \mathrm{k} \Omega, \mathrm{R} 2=10 \mathrm{M} \Omega, \mathrm{R} 3=1$
$\mathrm{M} \Omega, \mathrm{R} 4=200 \Omega, \mathrm{R} 5=10 \mathrm{k} \Omega, \mathrm{R} 6=10 \mathrm{k} \Omega, \mathrm{R} 7=100 \mathrm{k} \Omega$, $\mathrm{R} 8=10 \mathrm{~K} \Omega$.

5) Voltage monitoring circuit (Fig. 6): Op-amp: LM 358, $\mathrm{R} 1=\mathrm{R} 2=\mathrm{R} 3=\mathrm{R} 4=1 \mathrm{M} \Omega, \mathrm{R} 5=\mathrm{R} 6=10 \mathrm{~K} \Omega$.

\section{REFERENCES}

[1] D. Linden and T. B. Reddy, Handbook of Batteries, 3rd ed., McGrawHill, 2001.

[2] Jian Cao, Nigel Schofiled and. Ali Emadi, "Battery balancing methods: A comprehensive review", in Proc. IEEE Vehicle Power and Propulsion Conference, September 3-5, 2008, Harbin, China.

[3] Electronic Publication: BQ76PL 102 Datasheet, "Power LAN DualCell Li-Ion Battery Monitor with Power Pump Cell Balancing", Texas Instrument.

[4] S. K. Mandal, P. S. Bhojwani, S. P. Mohanty, and R. N. Mahapata, "IntellBatt: Towards smarter battery design," in Proc. 45th Annual ACM/IEEE Design Automation Conference, June 8-13, 2008, pp. 872-877.

[5] S.Ci, J. Zhang, H. Sharif, and M. Alahmad "A novel design of adaptive reconfigurable multicell battery for power-aware embedded networked sensing system," in Proc. 2007 IEEE Global Telecommunication Conference, Nov. 26-30, 2007, pp. 1043-1047.

[6] H. Visairo and P. Kumar, "A reconfigurable battery pack for improving power conversion efficiency in portable devices", in Proc. 7th International Caribbean Conference on Devices, Circuits and Systems, Apr. 28-30, 2008, Mexico.

[7] R. Rao, S. Vrudhula, and N. Chang, "Battery optimization vs energy optimization: Which to choose and when," in Proc. 2005 IEEE/ACM International Conference on Computer-Aided Design, pp. 439-445

[8] F. Zhang, Z. Shi, and W. Wolf, "A dynamic battery model for codesign in cyber-physical systems," in Proc. 29th IEEE International Conference on Distributed Computing Workshops, June 22-26, 2009, pp. 51-56.

[9] P. S. Sausen, M. A. Spohn, F. Salvadori, M. de Campos, A. Perkusich, "Applying dynamic power management with mode switching in wireless sensor networks," in Proc. 34th Annual Conference of IEEE Industrial Electronics Society, Nov. 10-13, 2008, pp. 1713-1717.

[10] T. Kim, W. Qiao, and L. Qu, "Series-connected reconfigurable multicell battery: A novel design towards smart batteries," in Proc. IEEE Energy Conversion Congress and Exposition 2010, Atlanta, GA, USA, Sept. 12-16, 2010, pp. 4257-4263.

[11] M. Chen and G. A. Rincon-Mora, "Accurate electrical battery model capable of predicting runtime and I-V performance," IEEE Trans. Energy Conversion, vol. 21, no.2, pp. 504-511, June 2006

[12] J. Manwell, J. Mcgowan, "Extension of the kinetic battery model for wind/hybrid power system," in Proc. $5^{\text {th }}$ European Wind Energy Association Conference (EWEC '94), 1994, PP. 1182-1187 